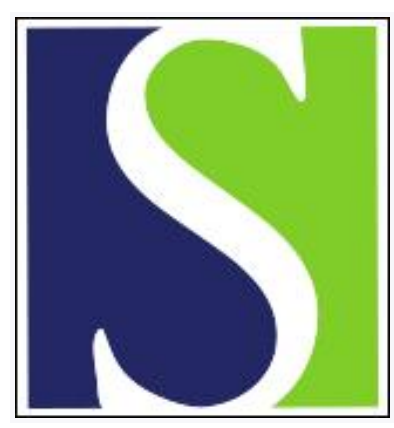

Scand J Work Environ Health 2000;26(4):299-305

https://doi.org/10.5271/sjweh.546

Issue date: Aug 2000

Acute response to precision, time pressure and mental demand during simulated computer work

by Birch $L$, Juul-Kristensen B, Jensen $C$, Finsen L, Christensen $H$

The following article refers to this text: SJWEH Supplements 2007;(3):68-75

Key terms: computer mouse; electromyography; experimental set-up; exposure interaction; forearm; shoulder; visual display unit

This article in PubMed: www.ncbi.nlm.nih.gov/pubmed/10994795

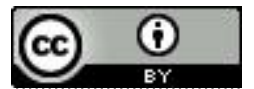




\title{
Acute response to precision, time pressure and mental demand during simulated computer work ${ }^{1}$
}

\author{
by Laila Birch, MS, ${ }^{2}$ Birgit Juul-Kristensen, ${ }^{3}$ Chris Jensen, PhD, ${ }^{2}$ Lotte Finsen, PhD, ${ }^{2}$ Hanne Christensen, \\ $P h D^{2}$
}

Birch L, Juul-Kristensen B, Jensen C, Finsen L, Christensen $H$. Acute response to precision, time pressure and mental demand during simulated computer work. Scand J Work Environ Health 2000;26(4):299-305.

\begin{abstract}
Objectives The electromyographic (EMG) activity of shoulder and forearm muscles was recorded during a standardized computer task with different combinations of time pressure, precision demands, and mental demands to study the interaction of these factors and their effect on muscular response during simulated computer work. Methods The computer task lasted 5 minutes, and it was performed by 14 female computer-aided design (CAD) operators during 8 exposure combinations that differed with respect to time pressure, precision demand, and mental demand. Performance (number of produced drawings, mouse clicks, and errors) were recorded. The EMG activity was recorded from the trapezius, infraspinatus, deltoid, and extensor digitorum muscles. An electrogoniometer was used to measure wrist postures and movements.

Results High time pressure (combined with low precision and low mental demands) resulted in higher EMG activity for all the muscles and in a small increase in the number of produced drawings. High precision demands caused a large reduction in the number of produced drawings, but not always a change in EMG activity. High precision demands and high mental demands led to no change or a reduction in muscle activity because the number of drawings was greatly reduced.

Conclusions The interaction between work pace and other exposure factors must be taken into account when the effects of changes in exposure demands on muscular response are predicted. Only then can it be predicted whether changing demands will constitute a risk of developing musculoskeletal disorders.
\end{abstract}

Key terms computer mouse, electromyography, experimental set-up, exposure interaction, forearm, shoulder, visual display unit.

In modern society the number of employees involved in computer work increases (1), and there are indications that musculoskeletal disorders are associated with computer work (2-6). A study of technicians [computer-aided design (CAD) operators] working intensively with a computer mouse or mouse-like input devices, such as a puck, showed that computer work was performed in constrained postures with repetitive movements of the upper arm, the wrist, and the fingers and that the load on the shoulder and forearm muscles was low but static (2). Exposures characterizing the computer work were high precision and high concentration. Even though the work pace is controlled by the computer operator himself, tight deadlines may lead to high time pressure, which is associated with musculoskeletal symptoms of the upper extremity $(7,8)$.

Increasing movement speed and precision demands lead to a greater shoulder muscle load $(9-11)$. Furthermore, experimental studies investigating the influence of mental demand and time pressure have reported an increase in the load on the shoulder and forearm muscles when these demands are increased (12-14).

A complex interaction exists between different exposures, and intervention concerning 1 exposure will often affect other exposures $(9,15)$.

Earlier studies have mostly dealt with 1 exposure in isolation while keeping others constant. The purpose of the present study was to investigate to what extent

1 The study was a part of the EGA (documentation and account of repetitive monotonous work) program.

2 Department of Research in VDU-work, National Institute of Occupational Health, Copenhagen, Denmark.

3 Department of Physiology, National Institute of Occupational Health, Copenhagen, Denmark.

Reprint requests to: Ms Laila Birch, National Institute of Occupational Health, Lers $\varnothing$ Parkallé 105, DK-2100 Copenhagen $\varnothing$, Denmark. [E-mail:Lb@ami.dk] 
different combinations of time pressure, precision, and mental demands influence muscular activity and productivity during computer work.

\section{Subjects and methods}

\section{Subjects}

Fourteen experienced female CAD operators were recruited from 149 operators participating in a questionnaire study at an engineering company (2). The subjects in our present study completed another questionnaire on the day of the experiment. Only CAD operators with at least 5 hours of daily CAD work were included. Because of the maximal exertion needed during the electromyographic (EMG) normalization, CAD operators who were pregnant or had experienced severe low-back or upperextremity trouble were excluded. Ten subjects reported symptoms of the neck or upper extremities on the day of the experiment, and 12 subjects reported symptoms during the week prior to the experiment. Only 2 subjects were free of pain both during the experiment and during the week prior to the experiment. The mean age of the subjects was 40 (range 28-52) years.
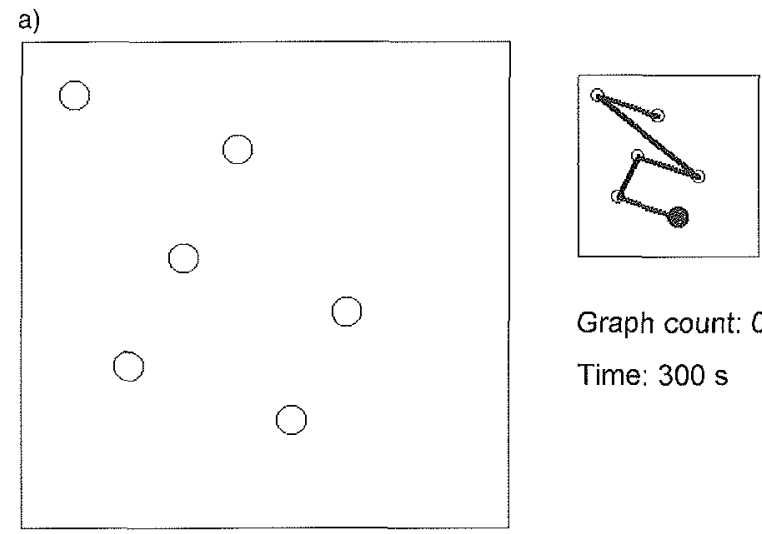

Graph count: 0

Time: $300 \mathrm{~s}$

b)
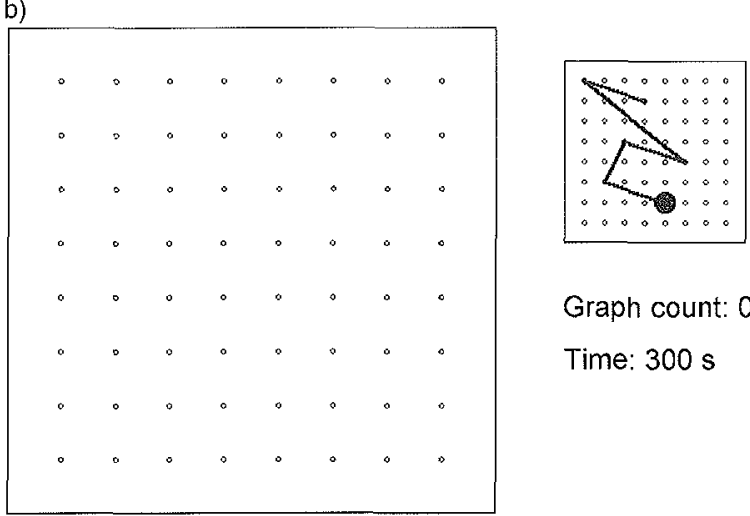

Graph count: 0

Time: $300 \mathrm{~s}$

Figure 1. Computer screen shown during the standardized worktask. ( $a=$ exposure of low precision combined with low mental demand, $b$ $=$ exposure of high precision combined with high mental demand)
The local ethics committee of Copenhagen approved the study, and all the subjects signed an informed consent document prior to the experiment.

\section{Procedure}

A laboratory at the company was used. The computer workstation was adjustable, and the subjects adjusted the height of the tables and chairs themselves. The design of the table insured a possibility for arm rest during the experiment. After performing maximum voluntary contractions (MVC) of the shoulder and forearm muscles, the subjects performed a standardized computer task using a puck on a digitizer, which was normally used by these operators. The same computer task was performed with 8 different exposure combinations of precision, time pressure and mental demands in random order. The subjects worked 5 minutes with each exposure combination, and the combinations were separated by at least 2-minute breaks. A week before the experiment the subjects were introduced to the worktask and trained the task for 30 minutes. Prior to the actual experiment, 2 more training sessions of 5 minutes' duration each were performed.

\section{Standardized worktask}

The computer task was performed using a puck on a digitizer. Circular targets were shown on the computer screen, and the task consisted of pointing the cursor to the targets that were activated by pressing a button on the puck. Lines were automatically drawn between consecutively activated targets, and the purpose was to activate targets in a specific order to duplicate a drawing that was shown in the upper right-hand corner of the computer screen (figure 1). As soon as a drawing was completed, another drawing popped up. Precision, time pressure, and mental demands could be set at 2 different levels each, high and low, giving 8 combinations of exposure. Each combination has been symbolized by the letters $t$ or $\mathrm{T}$ (time), $\mathrm{p}$ or $\mathrm{P}$ (precision), $\mathrm{m}$ or $\mathrm{M}$ (mental), lower case letters referring to low demands and upper case letters referring to high demands (eg, tPM denotes low time pressure, high precision and high mental demands).

High and low precision meant that the diameter of the target points were 4 pixels and 30 pixels, respectively, which in this set-up equaled movements with the puck of approximately 0.5 and $3.5 \mathrm{~mm}$, respectively (figure 1). For the high time pressure the subjects were instructed to complete as many drawings as possible within 5 minutes and told that the result would be stored. For the low time pressure the workpace was self-chosen, and the subjects were instructed to work in a relaxed, but continuous fashion.

During high mental demands the subjects had to distinguish relevant points from irrelevant points in a grid with $8 \times 8$ grid points. During low mental demands only the relevant points were visible (figure 1). 


\section{Performance}

The number of produced drawings in each 5-minute test period was registered by the specially designed software that was used for the standardized task. The number of errors, the number of clicks on the puck, and the distance that the cursor was moved on the screen (number of pixels) were also registered.

\section{Registration of wrist posture and movement}

A biaxial electrogoniometer connected to a data logger (Penny \& Giles Biometrics Ltd) was used to monitor angular wrist positions with a sampling frequency of $20 \mathrm{~Hz}$ (16). Calibration was made with regard to the range of motion (flexion-extension, radial-ulnar deviation) and neutral position with the arm hanging vertically along the side of the body and the hand totally relaxed. During each work situation the duration (\%time) of the low-angular velocity, designated as movement "pause" was calculated. Movement pause was defined as an angular velocity of $<1$ degree per second lasting for a least 500 milliseconds. Only the movement pause in the combined plane of flexion-extension and deviation has been reported.

\section{Electromyography}

After the skin of the subject had been shaved and cleaned with alcohol, bipolar surface electrodes (Ag-AgCl, type 7 0002-E, Medicotest A/S, Denmark) were placed over the medial deltoid muscle, the descending part of the trapezius muscle, the infraspinatus muscle, and the extensor digitorum muscle of the mouse-operating side with an interelectrode distance of $20 \mathrm{~mm}$ for electromyographic (EMG) registration. After amplification and filtering (bandwidth $10-400 \mathrm{~Hz}$ ) the EMG signals were sampled at $1024 \mathrm{~Hz}$ by a data logger (Logger Teknologi HB, Lund, Sweden) before they were transferred to a computer.

\section{Analysis of the electromyographic signals}

The EMG signals were full-wave, rectified, and rootmean-square (RMS) converted. For signals recorded during the standardized computer work, consecutive 100millisecond windows were used. For the analysis of the EMG signals obtained during the maximum voluntary contractions (MVC), a moving window of 1 second that was moved in 100-millisecond steps was used to find the maximum $\mathrm{EMG}$ value $\left(\mathrm{EMG}_{\max }\right)$, and this $\mathrm{EMG}_{\max }$ was used to normalize the worktask recordings.

\section{Maximum voluntary contractions}

MVC of the trapezius muscle, the deltoid muscle, the infraspinatus muscle, and the extensor digitorum muscles were isometric and measured with the subject in a sit- ting position and with a supported straight back. A straingauge-based dynamometer was used to measure the force. At least $3 \mathrm{MVC}$ were made for each muscle, each MVC lasted 5 seconds, and all the MCV were separated by 2 minutes. If the last MVC was larger than the prior MVC, another MVC was performed.

For the trapezius muscle and the medial deltoid muscle the subject performed bilateral shoulder elevation against vertical straps placed just proximal to the elbow joint of the upper arms, which were abducted 90 degrees.

For the infraspinatus muscle an outward rotation of the upper arm was performed with the strap horizontal and placed over the wrist of the semipronated forearm, and the elbow was flexed 90 degrees.

For the extensor digitorum muscle the subject performed an isometric dorsal extension of the hand against a strap placed just proximal to knuckles of the 4 ulnar fingers. The elbow was flexed 90 degrees, and the forearm was fixed to the surface just distal to the elbow joint and proximal to the wrist.

\section{Statistics}

The differences between the 8 conditions of the computer task were tested for statistical significance using a Friedman repeated-measures analysis of variance on ranks. If the differences were significant, multiple comparisons were carried out using the Student-NewmanKeuls method. A significance level of $\mathrm{P} \leq 0.05$ was used.

\section{Results}

\section{Performance}

The number of produced drawings during each 5-minute period, the number of errors and mouse clicks, and the distance moved on the screen (pixels) were all significantly influenced by the combinations of time pressure, precision, and mental demands $(\mathrm{P}<0.001$ for all) (figure 2).

Thus high time pressure combined with low precision and low mental demand caused a small increase in the number of drawings produced and the number of mouse clicks and pixels, but time pressure had no influence on the number of errors.

When the demand for precision was increased, a smaller number of drawings was produced. In general the number of clicks per drawing was larger if the demand for precision was high, whereas the number of errors per drawing decreased if the demand for precision was increased but only in combinations with high mental demand. Increasing the demand for precision increased the number of pixels per drawing, but only when the mental demand was low. 

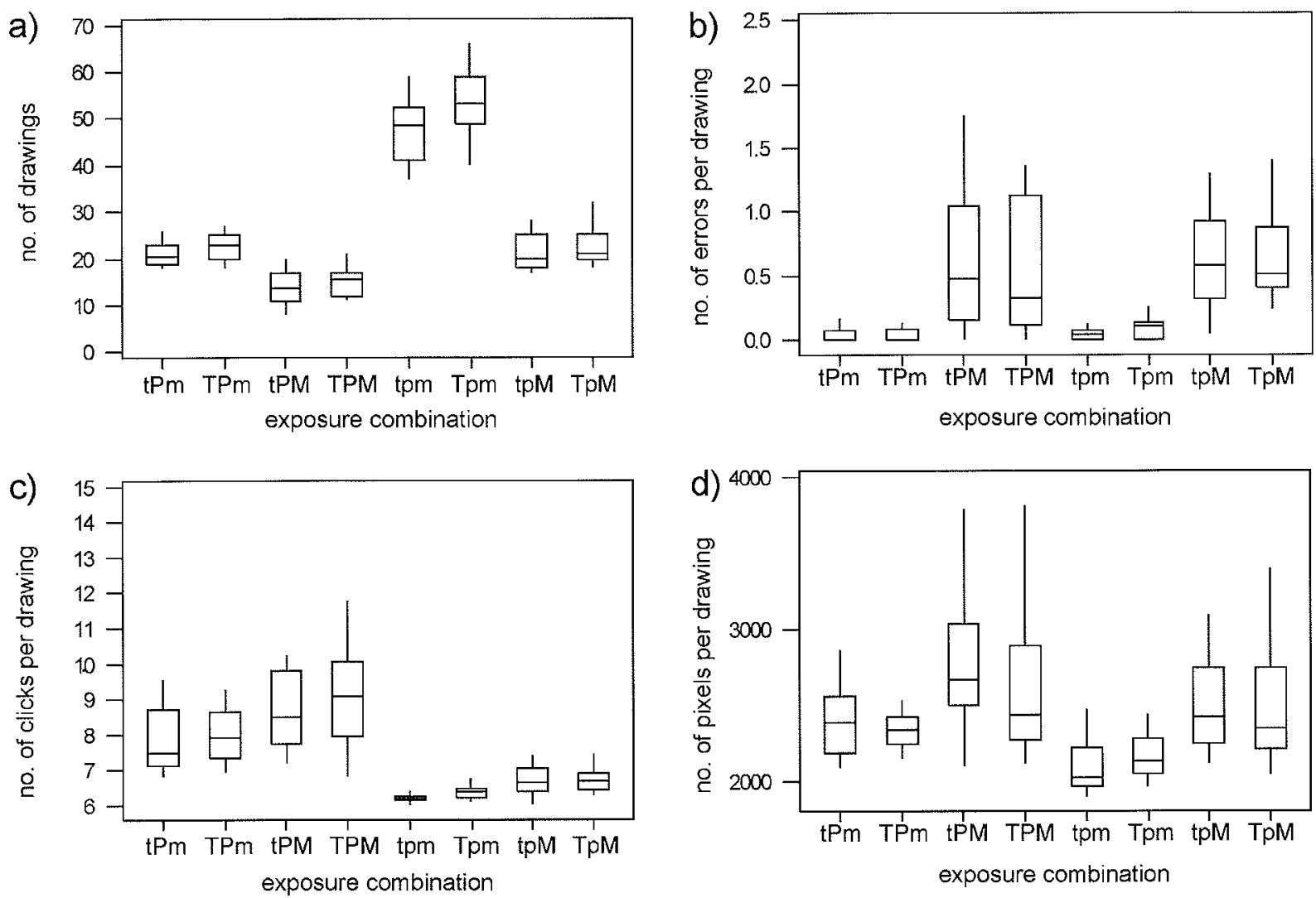

Figure 2. Box and whisker plots with medians and $25-75$ percentiles for the productivity (total number of drawings) (a), the number of errors per drawing (b), the number of mouse clicks per drawing (c), and the number of screen pixels the cursor was moved per drawing during 8 exposure combinations of time pressure $(t, T)$, precision $(p, P)$, and mental $(m, M)$ demands. (lower case letters $=$ low level, upper case letters $=$ high level, number of subjects $=14$ )

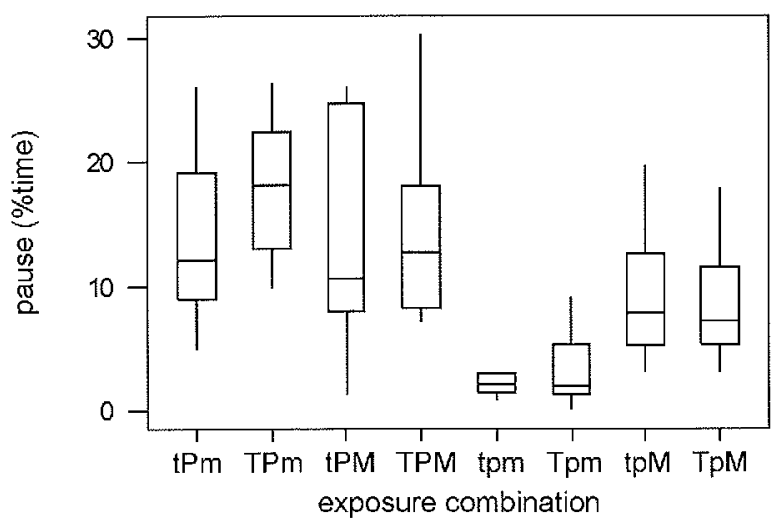

Figure 3. Box and whiskers plots with medians and $25-75$ percentiles showing the duration in movement "pause" of the hand during 8 exposure combinations of time pressure $(t, T)$, precision $(p, P)$ and mental $(\mathrm{m}, \mathrm{M})$ demands. (lower case letters $=$ low level, upper case letters = high level, number of subjects $=12$ ).

Increasing the mental demand caused a decrease in the number of drawings and increases in the numbers of errors, mouse clicks and pixels per drawing.

The reduction in the number of produced drawings due to an increase in precision demands or an increase in mental demands was almost as large as when the precision and mental demands were increased simultaneously.

\section{Postures and movements of the wrist}

The wrist postures were similar in the 8 tests. For $50 \%$ of the time the wrist was extended above 33 degrees on the average (range between subjects: 18-50 degrees), and it was ulnar deviated above 14 degrees for $50 \%$ of the time on the average (range between subjects 7 degrees radial -27 degrees ulnar deviation). The wrist movement velocities were between 0 and 3 degrees/second $50 \%$ of the time and below 11-12 degrees/second $90 \%$ of the time. The velocities were significantly reduced by an increase in precision or mental demands $(\mathrm{P}<0.001)$. Thus the median velocity of the wrist deviation during the exposure combinations tpm, tPm, and tpM were $2.7,0.6$, and 1.2 degrees/second, respectively.

The duration of the movement pause of the wrist was also influenced by the test condition $(\mathrm{P}<0.001)$ (figure 3 ). Time pressure did not affect the duration of the movement pause of the wrist, but high precision generally caused a longer total duration of the movement pause. When the mental demand was increased, the duration of 
the movement pause also increased, but only when high mental demand was present in combination with a low demand for precision (tpm, Tpm versus tpM, TpM).

\section{Muscular activity}

The normalized EMG activity of all the muscles differed significantly between some of the 8 exposure combinations $[\mathrm{P}<.001$ for all muscles except the trapezius muscle $(P=0.003)$ ] (figure 4). For all the muscles the EMG activity during the combination Tpm was higher than the activity during all the other combinations. For the trapezius muscle the EMG activity levels during all the exposure combinations except Tpm were similar (ie, precision and mental demands only affected the EMG activity of the trapezius muscle when the EMG activity levels recorded during the combinations TPM, TPm, and TPM were compared with those of Tpm). High time pressure combined with high precision and high mental demand resulted in a higher EMG activity level for the extensor digitorum, deltoid, and infraspinatus muscles. The lastmentioned muscle was also affected by time pressure when tpM and TpM were compared. When Tpm and TPm were compared, the EMG activity levels were lower for all the muscles during the demand for high precision. For the deltoid muscle a lower EMG activity level was found during low precision when the combinations TpM and TPM were compared. Thus, for the trapezius and deltoid muscles, there was no effect on the EMG activity when a change occurred in the demand for precision when the subjects worked at a self-chosen pace. For the infraspinatus muscle an effect of high precision was found for the combination Ptm versus ptm, and for the extensor digitorum muscle an effect of high precision was found for PtM versus ptM.

Apart from the lower activity for all the muscles during high mental demand, for Tpm versus TpM, the EMG activity levels for the extensor digitorum were lower during the high mental demand in Ptm versus PtM. For the deltoid and infraspinatus muscles the EMG activity was, in general, decreased by a change from low to high mental demand, especially when the precision demands were low (tpm and Tpm versus tpM and TpM).

\section{Discussion}

The reported EMG levels were comparable to those found in other laboratory studies and during real
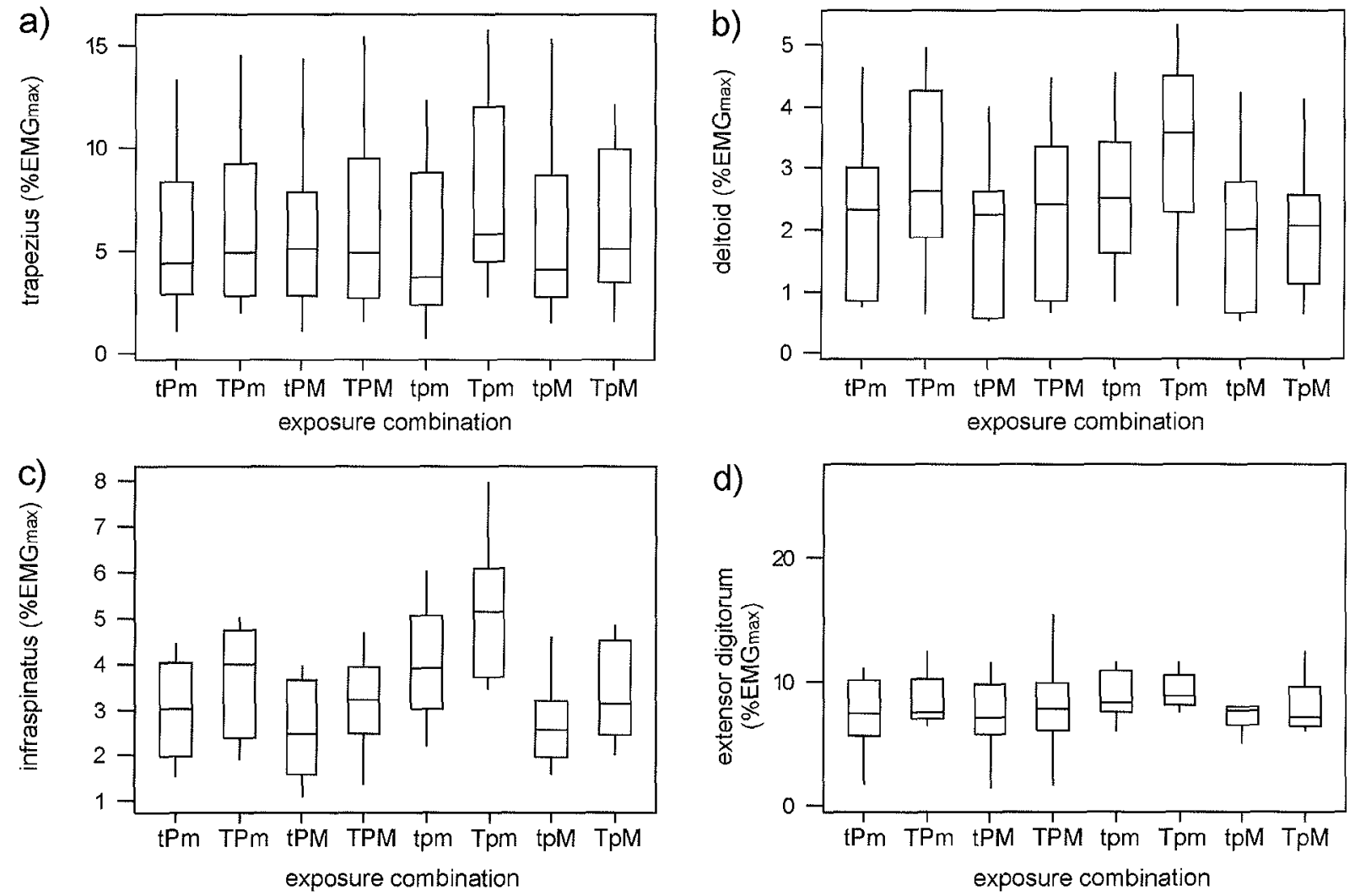

Figure 4. Box and whisker plots with medians and $25-75$ percentiles showing electromyographic activity (\%EMG $\mathrm{G}_{\max }$ ) of the trapezius muscle $(\mathrm{N}=14)$ (a), deltoid muscle $(\mathrm{N}=10)$ (b), infraspinatus muscle $(\mathrm{N}=9)(\mathrm{c})$, and extensor digitorum muscle $(\mathrm{N}=12)(\mathrm{d})$ during 8 different exposure combinations of time pressure $(t, T)$, precision $(p, P)$, and mental $(m, M)$ demands. (lower case letters = low level, upper case letters $=$ high level) 
computer work with reported EMG levels of 4-10 $\% \mathrm{EMG}_{\max }$ for the trapezius muscle and $7-8 \% \mathrm{EMG}_{\max }$ for the extensor digitorum muscle $(2,17,18)$. The hand postures also corresponded well with those reported in similar studies (19), although our wrist movement velocities were lower. However, it should be noted that our study was performed on female subjects. The results may therefore only be valid for women, as female computer operators differ from male operators in several respects. They report more symptoms than men do, and gender differences are found in work postures and EMG levels during computer work $(17,18)$.

This study showed that the productivity (number of produced drawings) during computer work depended on the combination of the 3 investigated factors. The muscle activity and the posture and movement registrations therefore reflected both the influence of the 3 factors per se and the influence of productivity.

Large differences were found in productivity between some exposure combinations, but high time pressure per se only introduced small increases in productivity when added to a given combination of precision and mental demands. Thus an optimal workpace close to maximum may exist for a given combination of precision and mental demands. Increasing the workpace is known to result in greater muscle load (20). The higher EMG activity in all the muscles during high time pressure (combined with low precision and mental demands) may have been caused by a faster movement speed accompanying the larger productivity (9). But the increase in productivity was small, and the stressful situation that was introduced by high time pressure may have had an influence on the muscle activity as well $(11,13)$.

The higher number of pixels that the cursor had been moved per drawing and the higher number of mouse clicks per drawing during high precision and high mental demands probably indicated that different work techniques were used. And, for higher mental demand, the very large increase in errors further indicated how important such factors are for the performance of computer operators. Surprisingly, the muscular response to the high demand for precision was either absent or it showed a decrease in muscle activity. However, when the very large reduction in productivity that accompanied high precision demands is taken into consideration, the lower workpace probably explained the lower muscle activity. As for the effect of increasing the mental demand, the observed decreases in muscle activity would also be explained by the lower productivity. Still it should be emphasized that both high precision and high mental demand have been reported to increase EMG activity in studies in which other work demands, such as workpace or work load, were constant $(9,11,13)$. In our study the increasing effect of precision and mental demand per se was indicated by the fact that, despite the very large reduction in productivity, the EMG levels were still very close to the EMG levels registered during low precision and low mental demands. Therefore, it seems that stabilizing the shoulder joint, wrist, and fingers during precision work has a strong influence on muscular response. The lack of a decrease in activity in the trapezius muscle during high mental load in spite of the large reduction in productivity supported the hypothesis of the trapezius being a muscle specifically vulnerable to mental load (14). An increase in EMG activity has also been found in the forearm extensors due to mental load (12) although, in our study, the influence of a lower workpace seemed to dominate.

In conclusion, the effects of high precision and mental demands during computer work may not inevitably cause higher muscle activity levels, as reported in other studies. Therefore, it may be difficult to predict whether changing demands will constitute a risk of developing musculoskeletal disorders during real work. In our study the workpace or productivity was allowed to vary, as it would during real work, and the effect of working with high precision or mental demands sometimes brought about a reduction in muscle activity due to the considerable decrease in productivity. On the other hand, a reduction in precision or mental demands did not induce much higher muscle activity levels even though the productivity increased considerably.

\section{Acknowledgments}

We are grateful to HB Olsen for programming the software used for the standardized computer task.

\section{References}

1. Arbejdsmiljøinstituttet. Danske lønmodtageres arbejdsmiljø og helbred 1990-95 [Danish work environment cohort study]. København: Arbejdsmiljøinstituttet, 1997.

2. Jensen C, Borg V, Finsen L, Hansen K, Juul-Kristensen B, Christensen $\mathrm{H}$. Job demands, muscle activity and musculoskeletal symptoms in relation to work with the computer mouse. Scand J Work Environ Health 1998;24(5):418-24.

3. Punnett L, Bergqvist U. Visual display unit work and upper extremity musculoskeletal disorders: a review of epidemiological findings. Solna: National Institute for Working Life, 1997. Ergonomic Expert Committee document, no 1.

4. Karlqvist L, Hagberg M, Köster M, Wenemark M, Ånell R. Musculoskeletal symptoms among computer assisted design (CAD) operators and evaluation of a self-assessment questionnaire. Int J Occup Environ Health 1996;2:185-94.

5. Fogleman M, Brogmus G. Computer mouse use and cumulative trauma disorders of the upper extremities. Ergonomics 
1995;38(12):2465-75.

6. Tittiranonda P, Burastero S, Rempel D. Risk factors for musculoskeletal disorders among computer users. Occup Med State Art Rev 1999;14(1):17-38.

7. Hales TR, Sauter SL, Peterson MR, Fine LJ, Putz-Anderson V, Schleifer LR, et al. Musculoskeletal disorders among visual display terminal users in a telecommunications company. Ergonomics 1994;37(10):1603-21.

8. Faucett J, Rempel D. VDT-related musculoskeletal symptoms: interactions between work posture and psychosocial work factors. Am J Ind Med 1994;26:597—612.

9. Laursen B, Jensen BR, Sjøgaard G. Effect of speed and precision demands on human shoulder muscle electromyography during a repetitive task. Eur J Appl Physiol 1998;78(6):5448.

10. Milerad E, Ericson MO. Effects of precision and force demands, grip diameter, and arm support during manual work: an electromyographic study. Ergonomics 1994;37(2):25564.

11. Westgaard RH, Bjørklund R. Generation of muscle tension additional to postural muscle load. Ergonomics 1987; 30(6): $911-23$.

12. Finsen L, Søgaard K, Jensen C, Olsen HB, Borg V, Christensen $\mathrm{H}$. Muscle activity during prolonged computer work with mouse. In: Finnish Institute of Occupational Health, PREMUS-ISEOH '98 3rd International Scientific Conference on Prevention of Work-related Musculoskeletal Disorders 13th International Symposium on Epidemiology in Occupational Health 21-25 Sept 1998. Helsinki: Finnish Institute of Occupational Health, 1998;118.

13. Lundberg U, Kadefors R, Melin B, Palmerud G, Hassmén P, Engström M, et al. Psychophysiological stress and EMG ac- tivity of the trapezius muscle. Int J Behav Med 1994; 1(4):354-70.

14. Wærsted M, Westgaard RH. Attention-related muscle activity in different body regions during VDU work with minimal physical activity. Ergonomics 1996;39(4):661-76.

15. Fitts PM. The information capacity of the human motor system in controlling the amplitude of movement. J Exp Psychol 1954:47(6):381-91.

16. Hansson G-Å, Balogh I, Ohlsson K, Rylander L, Skerfving S. Goniometer measurement and computer analysis of wrist angles and movements applied to occupational repetitive work. J Electromyogr Kinesiol 1996;6(1):23-35.

17. Karlqvist L, Bernmark E, Ekenvall L, Hagberg M, Isaksson A, Rostö T. Computer mouse and trackball operation: similarities and differences in posture, muscular load and perceived exertion. Int J Ind Ergon 1999;23:157—69.

18. Karlquist LK, Bernmark E, Ekenvall L, Hagberg M, Isaksson A, Rostö T. Computer mouse position as a determinant of posture, muscular load and perceived exertion. Scand J Work Environ Health 1998;24(1):62-73.

19. Karlqvist L, Hagberg M, Hansson G- $\AA$, Mattsson GH, Neelakantan G, Skantze C, et al. God arbetsmiljö vid bildskärmsarbete med datormus i den grafiska branschen [Good working environments for graphics industry VDU operators using computer mouse]. Solna: Arbetslivsinstitutet, 1995:142. Arbete och Hälsa 21.

20. Mathiassen SE, Winkel J. Physiological comparison of three interventions in light assembly work: reduced work pace, increased break allowance and shortened working days. Int Arch Occup Environ Health 1996;68:94-108.

Received for publication: 18 August 1999 